\title{
PENGUKURAN KOEFISIEN REAKTIVITAS DAYA REAKTOR RSG-GAS
}

\section{MEASUREMENT OF RSG-GAS REACTOR POWER REACTIVITY}

\author{
Susanto ${ }^{1}$, Sukarno Sigit' ${ }^{2}$, Suparjo ${ }^{3}$ \\ 1,2,3PRSG-BATAN, Kawasan Puspiptek Gd.30, Serpong, 15310 \\ Sukarnosigit250@gmail.com
}

Diterima : 21 Juli' 2020, diperbaiki : 22 Agustus 2020, disetujui : 11 September 2020

\begin{abstract}
ABSTRAK
PENGUKURAN KOEFISIEN REAKTIVITAS DAYA REAKTOR RSG-GAS. Koefisien reaktivitas daya (KRD) adalah parameter neutronik yang sangat penting untuk keselamatan operasi reaktor. Koefisien reaktivitas daya merupakan kombinasi dari koefisien reaktivitas doppler, moderator dan void. Koefisien reaktivitas daya RSG-GAS pernah diukur pada saat teras pertama, teras reaktor RSG-GAS telah dikonversi dari teras oksida (U3O ${ }_{8}$-AL) ke teras silisida $\left(\mathrm{U}_{3} \mathrm{Si}_{2} \mathrm{Al}\right)$ sehingga perlu dilakukan pengukuran ulang. Koefisien reaktivitas daya didesain bernilai negatif. Tujuan dari penelitian ini adalah untuk menghitung koefisien reaktivitas daya reaktor RSG-GAS melalui experimen penaikan daya. Koefisien reaktivitas daya ditentukan dengan menaikkan daya dari 1 - 15 MW secara bertahap dengan posisi batang kendali bank tetap dan batang kendali pengatur berubah. Perubahan reaktivitas ditentukan sesuai dengan posisi batang kendali pengatur. Dari hasil perhitungan diketahui koefisien reaktivitas daya ratarata sebesar -1.028 sen/MW dan akan semakin negatif mengikuti kenaikan daya. Hal ini terjadi karena kenaikan daya reaktor akan meningkatkan temperatur bahan bakar yang mengakibatkan terjadinya efek doppler. Selain itu daya moderasi moderator akan menurun akibat kenaikan suhu pendingin reaktor. Nilai koefisiean reaktivitas daya teras silisida lebih rendah dibanding teras oksida (KRD teras oksida $=1.97$ sen/MW). Hal ini disebabkan karena pembangkitan panas pada teras oksida untuk tingkat muatan uranium sebesar $250 \mathrm{gr}$ lebih tinggi dibanding silisida (oksida $1.87 \mathrm{~W} / \mathrm{gr}$, silisida $1.85 \mathrm{~W} / \mathrm{gr}$ ) sehingga efek doppler yang terjadi lebih tinggi. Namun jika dibandingkan dengan beberapa reaktor riset lainnya, nilai KRD RSGGAS realtif lebih besar. Dengan nilai KRD yang negatif dan semakin negatif mengikuti kenaikan daya reaktor maka reaktor dapat dioperasikan dengan stabil dan aman.
\end{abstract}

Kata Kunci : reaktivitas, daya, batang kendali pengatur.

\section{ABSTRACT}

MEASUREMENT OF REACTIVITY COEFFICIENT OF RSG-GAS REACTORS. The power reactivity coefficient (KRD) is a neutronic parameter which is very important for the safety of reactor operation. The power reactivity coefficient is a combination of the doppler, moderator and void reactivity coefficients. The power reactivity coefficient of RSG-GAS was measured at the time of the first core, the RSG-GAS reactor core had been converted from an oxide core (U3O8-AL) to a silicide core (U3Si2Al) so it was necessary to re-measure it. The power reactivity coefficient is designed to be negative. The purpose of this study is to calculate the power reactivity coefficient of the RSG-GAS reactor through an experimental power increase. The power reactivity coefficient is determined by increasing the power from 1 - $15 \mathrm{MW}$ gradually with the position of the bank control rod fixed and the control rod changing. The change in reactivity is determined according to the position of the control rod. From the calculation, it is known that the average power reactivity coefficient is -1.028 cents / MW and will be more negative as the power increases. This happens because the increase in reactor power will increase the temperature of the fuel which results in the Doppler effect. In addition, the 
moderating power of the moderator will decrease due to the increase in reactor coolant temperature. The reactivity coefficient value of the silicide core was lower than that of the oxide core (KRD of the oxide core $=1.97$ cents $/ M W)$. This is because the heat generation in the oxide core for the uranium charge level is $250 \mathrm{gr}$ higher than the silicide $(1.87 \mathrm{~W} / \mathrm{gr}$ oxide, 1.85 $W / g$ silicide) so that the doppler effect that occurs is higher. However, when compared with several other research reactors, the KRD RSG-GAS value is relatively higher. With a negative and more negative KRD value following the increase in reactor power, the reactor can be operated stably and safely.

Keywords: reactivity, power, control rod control.

\section{PENDAHULUAN}

\section{Peaktor RSG-GAS adalah}

reaktor tipe MTR (Material Testing Reaktor) menggunakan reflektor berilium dan air ringan sebagai moderator dan pendingin. Daya nominal $30 \mathrm{MW}$ (termal) dihasilkan oleh 40 elemen bahan bakar standar (FE) dan 8 elemen bahan bakar kontrol (CE) pada posisi grid $10 \times 10$ teras. Reaktor RSGGAS memiliki 8 posisi grid teras dari perangkap fluks neutron untuk mendapatkan fluks neutron termal yang tinggi. Pada daya $30 \mathrm{MW}$, fluks neutron termal rata-rata $2 \times 10^{14}$ neutron / $\mathrm{cm}^{2} \mathrm{~s}^{[1]}$. Bahan bakar yang digunakan adalah $\mathrm{U}_{3} \mathrm{Si}_{2} \mathrm{Al}$ dengan pengkayaan kurang dari 19,75 \% dan kerapatan $2.96 \mathrm{~g} / \mathrm{cc}^{[2]}$

Reaktor RSG-GAS telah beroperasi selama 32 tahun,untuk itu perlu dilakukan pengukuran beberapa parameter reaktor untuk menjamin keselamatan operasi reaktor. Beberapa pengukuran parameter keselamatan yang telah dilakukan adalah pengukuran fraksi bakar, batang kendali, fluks neutron termal dan spektrum neutron ${ }^{[3]}$.

Selama operasi reaktor nuklir ada dua efek dasar yang bekerja pada perubahan reaktivitas. Efek pertama akibat perubahan temperatur moderator yang terkait dengan karakteristik moderator. Efek kedua perubahan daya reaktor (suhu bahan bakar) yang disebut efek daya. Kedua efek ini disebut sebagai koefisien reaktivitas yang mempengaruhi pola operasi reaktor. Untuk itu, koefisien reaktivitas sangat penting untuk keselamatan operasi reaktor ${ }^{[4]}$. Sehingga banyak penelitian yang dilakukan untuk menghitung dan mengukur parameter tersebut untuk keselamatan operasi reaktor seperti pada Tabel 1. Dari Tabel 1 dapat dilihat belum ada peneltian yang membahas mengenai koefisien reaktivitas daya

Koefisien reaktivitas daya merupakan parameter keselamatan yang bernilai negatif untuk stabilitas dan keselamatan operasi reaktor nuklir ${ }^{[5]}$. Koefisien reaktivitas daya adalah kombinasi dari koefisien reaktivitas Doppler, moderator dan void ${ }^{[6]}$. Hal ini dinyatakan sebagai perubahan reaktivitas per perubahan daya, $\Delta \rho / \Delta p$. Koefisien reaktivitas daya bernilai lebih negatif pada akhir siklus oleh perubahan koefisien temparatur moderator ${ }^{[7]}$. Koefisien reaktivitas daya pernah diukur pada saat teras pertama reaktor RSGGAS dengan nilai sebesar 1.976 sen $/ \mathrm{MW}^{[8]}$. Saat ini teras reaktor RSG-GAS sudah dikonversi dari teras oksida (U3O- $-\mathrm{AL})$ ke teras silisida dengan tingkat kerapatan dan jumlah muatan uranium persatu elemen bahan bakar sama (2.96 g/cc dan 250 gram $)^{[9]}$

Sehingga tujuan dari penelitian ini adalah melakukan pengukuran ulang koefisien reaktvitas daya untuk teras 
silisida. Dalam penelitian ini dibatasi hanya pada perhitungan koefisien reaktivitas daya dan tidak dilakukan perhitungan pengaruh suhu terhadap reaktivitas reaktor.

Tabel 1 Daftar penelitian terkait

\begin{tabular}{|c|c|c|c|}
\hline No & $\begin{array}{l}\text { Nama Peneliti dan } \\
\text { Tahun Penelitian }\end{array}$ & Judul Penelitian & Fokus Penelitian \\
\hline 1 & $\begin{array}{l}\text { Pardi, Purwadi, } \\
2020\end{array}$ & $\begin{array}{l}\text { Analisis nilai reaktivitas } \\
\text { batang kendali teras } \\
\text { RSG-GAS Setelah } 30 \\
\text { tahun beroperasi }\end{array}$ & $\begin{array}{l}\text { Penelitian ini memfokuskan pada } \\
\text { perhitungan reaktivitas batang kendali } \\
\text { reaktor RSG-GAS dilakukan dengan } \\
\text { metode difusi menggunakan program } \\
\text { komputer WIMSD-5B dan Batan-3DIFF. }\end{array}$ \\
\hline 2 & $\begin{array}{l}\text { Tukiran Surbakti } \\
\text { Purwadi }\end{array}$ & $\begin{array}{l}\text { Analysis of Neutronic } \\
\text { Safety Parameters of the } \\
\text { Multi-Purpose Reactor- } \\
\text { Gerrit Augustinus } \\
\text { Siwabessy (RSG-GAS) } \\
\text { Research Reactor at } \\
\text { Serpong }\end{array}$ & $\begin{array}{l}\text { Penelitian ini memfokuskan pada } \\
\text { perhitungan parameter keselamatan } \\
\text { seperti reaktivitas suhu bahan bakar, } \\
\text { reaktivitas densitas moderator dan } \\
\text { reaktivitas void }\end{array}$ \\
\hline 3 & $\begin{array}{l}\text { T.Surbakti, } \\
\text { P. Purwadi, } 2017\end{array}$ & 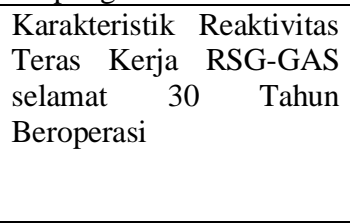 & $\begin{array}{l}\text { Penelitian ini memfokuskan pada } \\
\text { pengukuran reaktivitas padam, reaktivitas } \\
\text { padam stuck rod, reaktivitas lebih, } \\
\text { reaktivitas total, reaktivitas batang } \\
\text { kendali untuk teras kerja } 6 \text { s.d teras kerja } \\
91 \text { reaktor RSG-GAS }\end{array}$ \\
\hline 4 & Purwadi, 2017 & $\begin{array}{l}\text { Karakteristika Teras Rsg- } \\
\text { Gas Dengan Bakar Bakar } \\
\text { Silisida }\end{array}$ & $\begin{array}{l}\text { Penelitian ini memfokuskan pada } \\
\text { pengukuran karakteristika teras reaktor } \\
\text { RSG-GAS dengan material bahan bakar } \\
\text { yang berbeda namun pengkayaan dan } \\
\text { densitas yang sama. Parameter kinetik } \\
\text { yang diukur antara lain : Fraksi neutron } \\
\text { kasip, konstanta peluruhan neutron } \\
\text { serempak, umur generasi neutron, umur } \\
\text { neutron serempak, konstantan peluruhan } \\
\text { neutron rerata, konstanta peluruhan } \\
\text { neutron serempak. Sedangkan parameter } \\
\text { neutronik nya : koefisien reaktivitas } \\
\text { temperature bahan bakar, koefisien } \\
\text { reaktivitas temperature moderator }\end{array}$ \\
\hline 5 & $\begin{array}{l}\text { Tukiran S, Tagor } \\
\text { MS, } 2001\end{array}$ & $\begin{array}{lr}\text { Analisis Neutronik Teras } \\
\text { RSG-Gas } & \text { Berbahan } \\
\text { Bakar Silisida } & \end{array}$ & $\begin{array}{l}\text { Penelitian ini memfokuskan pada analisis } \\
\text { neutronik kelayakan pemakaian bahan } \\
\text { bakar silisida dengan muatan } 300 \text { gr. } \\
\text { Parameter neutronik yang dihitung adalah } \\
\text { : derajat bahan bakar, fraksi neutron kasip } \\
\text { efektif ( }(\text { eff). }\end{array}$ \\
\hline 6 & $\begin{array}{l}\text { Taswanda Taryo, } \\
\text { Rokhmadi, } 1998\end{array}$ & $\begin{array}{l}\text { Perhitungan Reaktivitas } \\
\text { Teras RSG-GAS dengan } \\
\text { Program Citation-3d }\end{array}$ & $\begin{array}{l}\text { Pada penelitian ini dilakukan perhitungan } \\
\text { Keff dengan mengunakan program } \\
\text { Citation 3-d }\end{array}$ \\
\hline
\end{tabular}


Pengukuran koefisien reaktivitas daya dilakukan dengan menaikan daya reaktor ke level tertentu dan melihat perubahan posisi batang kendali. Sebelum dilakukan pengukuran reaktivitas daya terlebih dahulu dilakukan kalibrasi batang kendali. Data ini diperlukan untuk menentukan harga reaktivitas akibat kenaikan daya reaktor.

\section{DASAR TEORI}

Reaktivitas teras akan berubah jika terjadi perubahan pada kondisi operasi reaktor, misalnya perubahan posisi batang kendali, modifikasi reflektor, susunan teras dan masuknya sumber neutron atau penyerap neutron ke dalam teras. Secara matematis reaktivitas dinyatakan dalam Persamaan $1^{[10]:}$

$$
\rho=\frac{\mathrm{k}_{\text {eff }-1}}{\mathrm{k}_{\mathrm{eff}}}
$$

Dengan $\rho$ adalah reaktivitas dan keff adalah faktor multiplikasi efektif.

Beberapa parameter koefisien reaktivitas di teras reaktor adalah koefisien reaktivitas bahan bakar, moderator, void. Koefisien reaktivitas daya (KRD) adalah penjumlahan dari koefisien reaktivitas suhu moderator, koefisien reaktivitas temperatur bahan bakar, dan koefisien reaktivitas void.

Koefsien reaktivitas daya pada dasarnya timbul dari perubahan temperatur, geometri teras dan kondisi fisik bahan bakar selama iradiasi. Koefisien reaktivitas daya tergantung pada koefisien reaktivitas suhu isothermal, kenaikan relatif suhu bahan bakar, kelongsong dan pendingin. Koefisien reaktivitas daya ditentukan dengan menggunakan Persamaan 2 [11][12].

$$
\mathrm{KRD}(0)=\frac{\mathrm{K}(\mathrm{P} 2)-\mathrm{K}(\mathrm{P} 1)}{\mathrm{P} 2-\mathrm{P} 1}
$$

Keterangan

$$
\begin{aligned}
\mathrm{KRD}(0) & =\text { koefisien reaktivitas } \\
& \text { daya static } \\
\mathrm{K}(\mathrm{P} 2)-\mathrm{K}(\mathrm{P} 1)= & \text { perubahan reaktivitas } \\
& \text { dari daya setimbang } \\
& \text { awal } \mathrm{P} 1 \text { ke daya se- } \\
& \text { timbang } \mathrm{P} 2
\end{aligned}
$$

Koefisien reaktivitas daya
didesain bernilai negatif, karena peningkatan level daya menyebabkan peningkatan suhu bahan bakar. Peningkatan suhu bahan bakar menyebabkan reaktivitas negatif akibat adanya fenomena efek doppler. Efek Doppler ialah fenomena pelebaran daerah neutron resonansi pada tampang lintang energi neutron seiring dengan kenaikan temperatur pada bahan bakar. Pelebaran daerah resonansi mempunyai efek yang sangat penting dalam fenomena penyerapan neutron resonansi (neutron dengan bentuk kurva energi yang tajam ${ }^{[13]}$. Selain itu peningkatan suhu bahan bakar menyebabkan meningkatnya suhu pendingin reaktor. Dengan meningkatnya suhu pendingin reaktor mengakibatkan daya moderasi pendingin akan turun dan menyebabkan reaktivitas negative. Hal ini terkait dengan sistem keselamatan pasive reaktor. Dengan mengetahui besaran koefisien reaktivitas daya akibat adanya perubahan daya, maka kestabilan reaktor dapat ditentukan. Kestabilan ini dapat dicapai apabila besaran koefisien reaktivitas daya dijaga tetap negatif untuk semua keadaan operasi ${ }^{[14]}$.

Perhitungan koefisien reaktivitas daya berkaitan dengan kurva harga batang kendali differensial dan integral batang kendali pengatur. Kurva diferensial dan integral terlebih dahalu dipastikan bentuknya benar untuk operasi normal. Kurva diferensial 
digunakan untuk mengetahui distribusi fluks neutron kearah aksial. Secara umum bentuknya adalah cosinus dengan puncak ada di tengah teras ${ }^{[15]}$. Sedangkan kurva batang kendali integral bentuknya mendekati kurva $S^{[16]}$. Kurva integral digunakan untuk mengetahui reaktivitas (sen) untuk setiap ketinggian batang kendali pengatur.

\section{METODOLOGI}

Sebelum menghitung koefisien reaktivitas daya, hal yang dilakukan adalah membuat kurva harga batang kendali diferensial dan integral batang kendali pengatur berdasarkan data kalibrasi batang kendali teras 99 dan memastikan betuk kurvanya benar. Setelah itu dilakukan pengambilan data pada tanggal 16 Agustus 2019, teras 99 berdasarkan ijin operasi no : 10 99/05/2019 dengan mengoperasikan sistem pendingin utama (sistem pendingin primer dan sekunder) dan sistem pendukung operasi reaktor lainnya. Berikut ini langkah-langkah untuk memperoleh data perhitungan koefisien reaktivitas daya :
1. Reaktor distabilkan pada daya rendah dan dijamin bahwa reaktor kritis dalam keadaan bebas sumber. Pada eksperimen ini reaktor distabilkan pada daya 1 MW dan semua batang kendali posisi bank.

2. Daya reaktor dinaikkan ke tingkat daya yang lebih tinggi dan posisi batang kendali bank sama dengan daya $1 \mathrm{MW}$, yang berubah adalah posisi batang kendali pengatur.

3. Mencatat posisi batang kendali pengatur.

4. Mencatat reaktivitas untuk setiap ketinggian batang kendali berdasarkan kurva integral.

5. Menghitung koefisien reaktivitas daya reaktor.

\section{HASIL DAN PEMBAHASAN}

Dari data kalibrasi batang kendali dihasilkan kurva harga batang kendali differensial dan integral untuk batang kendali pengatur seperti ditunjukkan pada Gambar 1 dan 2.

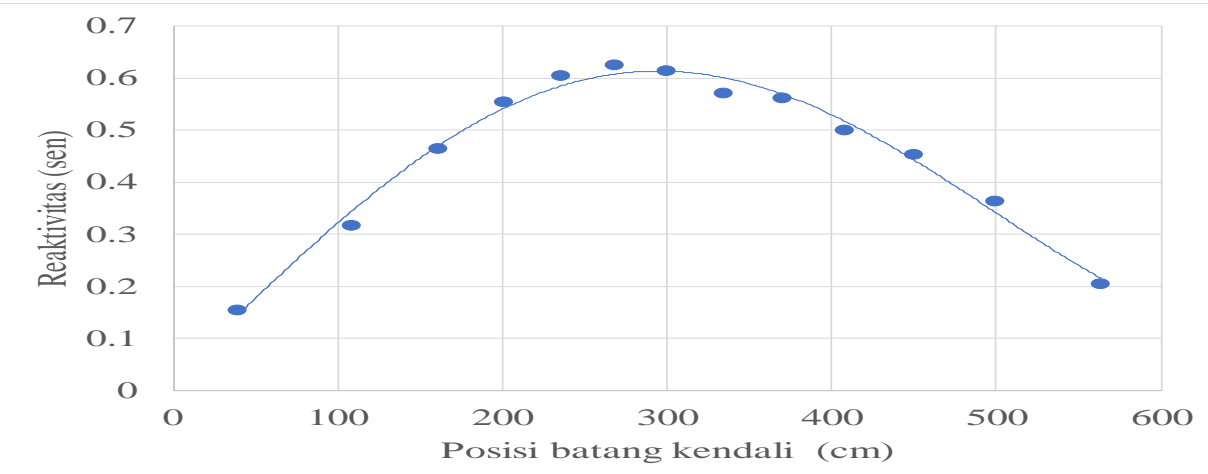

Gambar 1. Kurva harga batang kendali diferensial untuk batang kendali pengatur 
Seperti yang ditunjukkan pada Gambar 1, kurva diferensial digunakan untuk mengetahui distribusi fluks neutron ke arah aksial. Secara umum bentuknya adalah cosinus dengan puncak ada di tengah teras tetapi dalam hal ini tergantung pada posisi batang kendali dan waktu pengukuran. Pada bagian bawah fluks neutron lebih sedikit sehingga pergerakan batang kendali memberi efek yang kecil terhadap perubahan reaktivitas. Ketika batang kendali mendekati tengah teras efek batang kendali sangat besar sehingga perubahan harga batang kendali per perubahan satuan posisi menjadi besar. Ketika batang kendali bergerak dari tengah mendekati bagian atas maka perubahan harga batang kendali turun karena kerapatan fluks bagian atas berkurang.
Kurva batang kendali integral ditunjukkan pada Gambar 2, dimana bentuknya mendekati kurva $S$ seperti yang diharapkan. Berdasarkan Gambar 2 dapat dilihat bahwa slope kurva dan jumlah reaktivitas yang diinsersi per satuan posisi batang kendali terbesar terjadi dekat di tengah teras. Ini terjadi karena fluks neutron terbesar terjadi di tengah teras reaktor (posisi batang kendali / ketinggian).

Dengan meningkatnya daya reaktor, suhu moderator akan meningkat dan memberikan umpan balik reaktivitas negatif. Hal ini terjadi karena daya moderasi moderator berkurang dan memberikan reaktivitas negatif ke dalam teras.

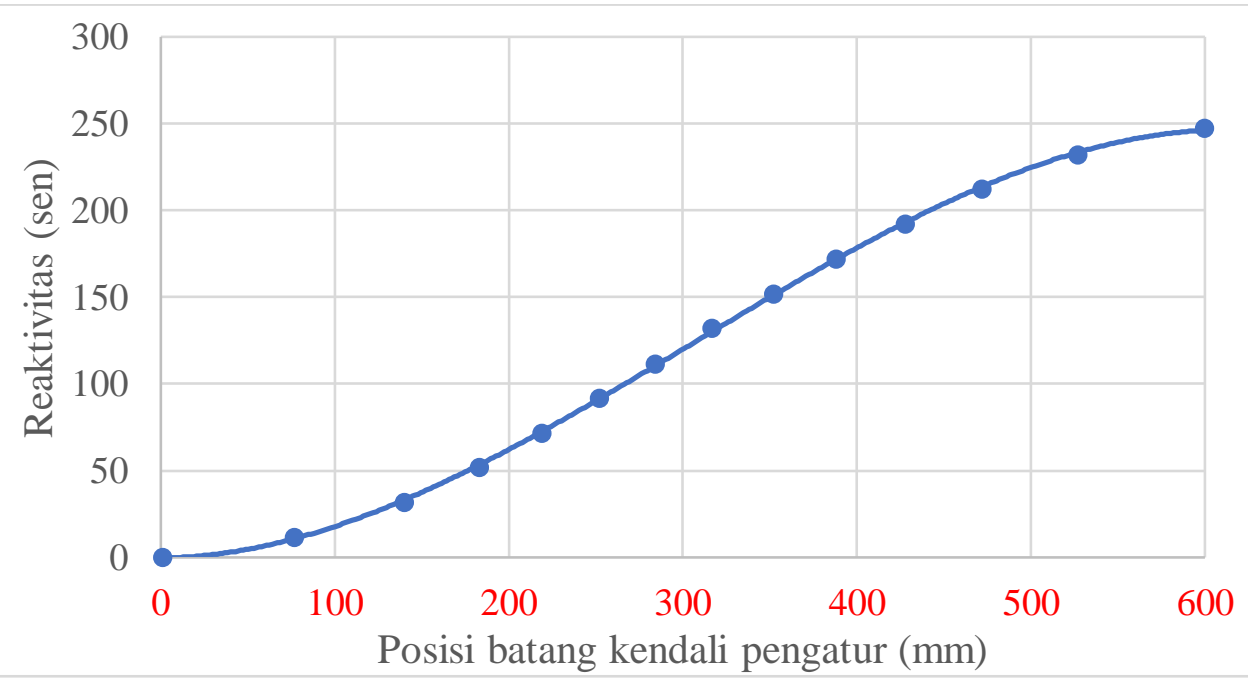

Gambar 2. Kurva harga batang kendali integral untuk batang kendali pengatur

Karena pengaruh koefisien temperatur yang negatif, sejumlah besar reaktivitas diperlukan untuk mengatasi kenaikan suhu agar reaktor tetap beroperasi pada 
level daya yang lebih tinggi dalam kondisi tunak. Untuk mempertahankan daya reaktor konstan pada tingkat yang diinginkan akibat kehilangan reaktivitas dikompensasi dengan menaikkan batang kendali pengatur.

Tabel 2 menyajikan hasil yang diperoleh dari pengukuran koefisien reaktivitas daya. Harga reaktivitas batang kendali pengatur berdasarkan kurva harga batang kendali integral dan nilai koefisien reaktivitas daya ditentukan dengan menggunakan Persamaan 2 dengan contoh perhitungan (untuk daya $5 \mathrm{MW}$ ) sebagai berikut :

$K(P 1)=136,792$ sen (reaktivitas pada daya awal $1 \mathrm{MW}$ )

$K(P 2)=140,442$ sen (reaktivitas pada daya $5 \mathrm{MW}$ )
Maka Koefisien reaktivitas daya (KRD) pada daya $5 \mathrm{MW}$ adalah

$$
\begin{aligned}
\mathrm{KRD}(0) & =\frac{\mathrm{K}(\mathrm{P} 2)-\mathrm{K}(\mathrm{P} 1)}{\mathrm{P} 2-\mathrm{P} 1} \\
\mathrm{KRD}(0) & =\frac{140,442-136,792}{5-1} \\
& =0,913 \text { sen/MW }
\end{aligned}
$$

Dari Tabel 2, dapat dilihat kehilangan reaktivitas untuk mencapat daya yang diinginkan (kolom reaktivitas) yang dikompensasi dengan menaikan

\begin{tabular}{|c|c|c|c|c|c|c|}
\hline No & $\begin{array}{l}\text { Daya } \\
\text { (MW) }\end{array}$ & $\begin{array}{l}\text { Posisi } \\
\text { Bank } \\
\text { (mm) }\end{array}$ & $\begin{array}{l}\text { Posisi } \\
\text { RR } \\
(\mathrm{mm})\end{array}$ & $\begin{array}{l}\text { Reaktivitas } \\
\text { (sen) }\end{array}$ & $\begin{array}{l}\text { Reaktivitas } \\
\text { total (sen) }\end{array}$ & $\begin{array}{l}\text { KRD } \\
\text { (sen/MW) }\end{array}$ \\
\hline 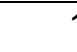 & 1 & 330 & 329 & 136,792 & 0 & 0 \\
\hline 2 & 2 & 330 & 332 & 138,518 & 1,825 & 0,913 \\
\hline 3 & 5 & 330 & 335 & 140,442 & 3,650 & 0,913 \\
\hline 2 & 10 & 330 & 345 & 146,507 & 9,714 & 1,079 \\
\hline 5 & 15 & 330 & 357 & 153,738 & 16,946 & 1,210 \\
\hline \multicolumn{6}{|c|}{ Koefisien reaktivitas daya rata-rata } & 1,028 \\
\hline
\end{tabular}
batang kendali dengan bentuk grafik seperti pada Gambar 3.

Tabel 2. Pengukuran koefisien reaktivitas daya rata-rata reaktor RSG-GAS 


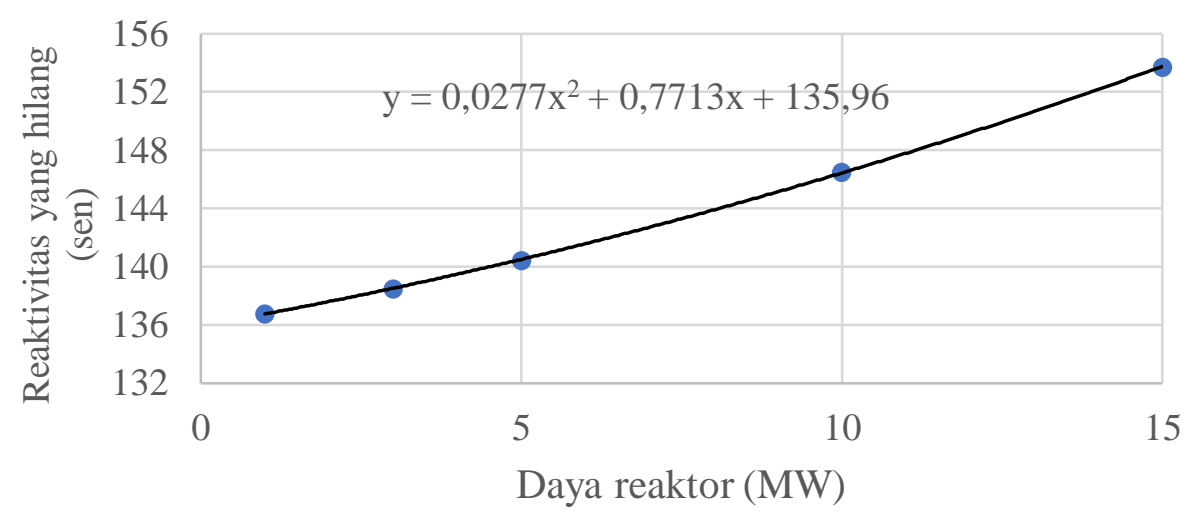

Gambar 3. Reaktivitas yang hilang versus daya reaktor

Tabel 3. Perbandingan nilai KRD RSG-GAS dengan reaktor riset lain

\begin{tabular}{lllll}
\hline No & Nama Reaktor & Nilai KRD & $\begin{array}{l}\text { Nilai KRD } \\
\text { dalam } \\
\text { satuan } \\
\text { cent/MW }\end{array}$ & Keterangan \\
\hline 1 & RSG-GAS & $\begin{array}{l}1,028 \\
\text { cent/MW }\end{array}$ & 1,028 & \\
\hline 2 & $\begin{array}{l}\text { IPR R1 Reactor at Nuclear } \\
\text { Technology Developtmen } \\
\text { Center (CTDN) Brazil }\end{array}$ & $\begin{array}{l}0,63 \\
\text { cent/KW }\end{array}$ & 0,00063 & \\
\hline 3 & Tehran reactor Research & $\begin{array}{l}0,89 \\
\text { pcm/KW }\end{array}$ & 0.107 e-3 & $\begin{array}{l}\text { Dengan } \beta \text { eff } \\
=0.0083\end{array}$ \\
\hline
\end{tabular}

Untuk hasil pengukuran koefisien reaktivitas daya rata-rata untuk setiap tingkat daya adalah sebesar $-1.028 \mathrm{sen} /$ MW dan cenderung makin negatif mengikuti kenaikan daya. Kenaikan daya reaktor mengakibatkan temperatur bahan bakar meningkat yang akan mengakibatkan pelebaran puncak energi neutron resonansi, yaitu neutron dengan bentuk kurva energi yang tajam berupa puncak dan lembah yang terlihat jelas pada kurva tarnpang lintang serapan mikroskopik dari U-238 - Sehingga pelebaran dari puncak neutron resonansi akan meningkatkan serapan neutron oleh U-238 (efek doppler). Hal ini mengakibatkan berkurangnya jumlah neutron termal yang diserap oleh $\mathrm{U}-235$ sehingga $\mathrm{K}_{\text {eff }}$

menjadi berkurang. Seperti pada Persamaan 1 maka jika Keff mengalami penurunan, reaktivitas yang terjadi di dalam teras akan ikut menurun. Dan juga dipengaruhi oleh reaktivitas negative akibat kenaikan suhu moderator.

Nilai KRD setelah konversi teras lebih kecil dari pada pada saat teras awal yaitu sebesar 1.976 sen / MW hal ini mungkin disebabkan oleh pembangkitan panas teras oksida lebih tinggi dibanding silisida (teras oksida $=$ 
$18.71 \mathrm{~W} / \mathrm{gram}$, teras silisida $=18.5$ W/gram ${ }^{[17]}$. Sehingga efek doppler yang terjadi akan lebih besar dan mengakibatkan reaktivitas negative pada teras oksida lebih besar dibanding silisida. Tetapi jika dibandingkan KRD reaktor riset yang lain (IPR R1 Reactor at Nuclear Technology Developtmen Center (CTDN) Brazil[18], Tehran research reactor ${ }^{[19]}$ dengan $\beta_{\text {eff }}{ }^{[20]}$ ) nilai koefisien reaktor RSG-GAS masih relative lebih besar seperti ditunjukan pada Tabel 2 . Dengan nilai koefisien reaktivitas yang negative dan cenderung makin negative mengikuti kenaikan daya maka reaktor dapat dioperasikan dengan stabil dan aman.

\section{KESIMPULAN}

Perhitungan koefisien reaktivitas daya dilakukan setelah pengukuran reaktivitas reaktor melalui pengaturan batang kendali pada setiap kenaikan daya. Koefisien reaktivitas daya reaktor sendiri bernilai negatif dengan bertambahnya daya karena efek doppler dan meningkatnya suhu pendingin reaktor. Nilai koefisien reaktivitas daya reaktor pada teras 99 rata-rata sebesar 1.028 sen /MW. Nilai ini lebih rendah dibanding teras pertama reaktor (teras oksida). Hal ini disebabkan pembangkitan panas oksida yang lebih tinggi dibanding teras silisida (oksida = $1,87 \mathrm{~W} / \mathrm{gr}$, silisida $1.85 \mathrm{~W} / \mathrm{gr}$ ) sehingga efek doppler pada teras oksida lebih tinggi dibanding silisida. Tetapi jika dibandingkan dengan nilai KRD reaktor riset lainnya, nilai KRD RSG-GAS relative lebih besar. Dengan nilai $K R D$ yang negative dan makin negatif mengikuti kenaikan daya maka reaktor dapat dioperasikan dengan aman dan stabil.

\section{DAFTAR PUSTAKA}

[1] I. Kuntoro, T.M. Sembiring, Desain teras alternative untuk Reaktor riset inovatif (RRI) dari aspek nutronik", Jurnal Teknologi Reaktor Nuklir, Vol.16, hal. 1-10 2014

[2] Laporan Analisis Keselamatan, PRSG-GAS Rev10.1, Desember 2011

[3] S. Pinem, P. H. Liem, T. M. Sembiring, and T. Surbakti, "Fuel Element Burnup Measurements For The Equilibrium LEU Silicide RSG GAS (MPR-30) Core Under a New Fuel Management Strategy," Ann. Nucl. Energy, vol. 98, 2016.

[4] Budi Rohman, "Reaktor Kartini," Koefisien Reaktivitas Suhu Bahan Bakar Pus. Pengkaj. Sist. dan Teknol. Pengawas. Instal. dan Bahan Nukl. Badan, 2010.

[5] M. Iqbal Hosan, M. A. M. Soner, K. A. Kabir, M. A. Salam, and M. Fazlul Huq, "Study on neutronik safety parameters of BAEC TRIGA research reaktor," Ann. Nucl. Energy, vol. 80, pp. 447450, 2015.

[6] M. H. Rabir, "Measurement Of The Power And Temparatur Reactivity Coefficients Of The RTP TRIGA reaktor," Nucl. Eng. Des., vol. 265, pp. 269-271, 2013.

[7] https://www.nrc.gov/docs/ML112 2/ML11223A207.pdf diakses pada tanggal 9/10/2020 pukul 08.28 am.

[8] RSG-GA.Siwabessy, Multipurpose Reactor Commisioning Tes 0 - 10.7 MW power, PRSG, BATAN, 1988

[9] T. Surbakti, "Analisis Kecelakaan Reaktivitas Teras RSG-GAS 
Berbahan Bakar Silisida, Prosiding Seminar ke-7 Teknologi dan Keselamatan PLTN Serta Fasilitas Nuklir, Bandung, Tahun 2002, ISSN : 0854-2910.

[10] T.Surbakti, P. Purwadi, "Karakteristik Reaktivitas Teras Kerja RSG-GAS selama 30 Tahun Beroperasi, Jurnal Penelitian Fisika dan Aplikasinya (JPFA) 7 (1), 13-26.

[11] John C.Lee, "Nuclear Reactor : Physics and Engineerting," John Wiley \& Sons, Inc, 2020.

[12] S. Dawahra, K. Khattab, and G. Saba, "Reactivity Temparatur Coefficients For The HEU and LEU fuel of the MNSR reaktor," Prog. Nucl. Energy, vol. 88, pp. 28-32, 2016

[13] S.Tukiran, Rokhmadi, 2007, "Analisis Koefisien Reaktivitas Moderator Pwr Dengan WimsAnltemperatur,Prosiding PPI PDIPTN, Yogyakarta : 10 Juli 2007, Hal 186-194,ISSN 0216 3128.

[14] J. S. Surian Pinem, Tukiran, "Pengukuran Parameter Kinetik Teras Silisida Dengan Kerapatan 2,96 g U/cc Reaktor RSG-GAS," J. Fis. Himpun. Fis. Indones., vol. 6, no. 0201, pp. 1549-1555.,
2004.

[15] C.S. Aldison., S.M.Aquilino, C.G. Alessandro,2012,

"Reconstruction of the Neutron Flux in a Slab Reactor", World Journal of Nuclear Science and Technology, 2, 181-186.

[16] H. Anglart, "Applied Reactor Technology”, KTH Royal Institute of Technology, 2011.

[17] Setiyanto, "Pengaruh Konversi Teras RSG-GAS Dari Oksida Ke Silisida Terhadap Kerapatan Gamma, Prosiding pertemuan dan presentasi ilmiah, Yogyakart :23-25 April 1996, ISSN 02163128.

[18] R. M. G. D. P. Souza and A. Z. Mesquita, "Measurements Of The Isothermal, Power And Temparatur Reactivity Coefficients Of The IPR-R1 TRIGA reaktor," Prog. Nucl. Energy, vol. 53, no. 8, pp. 11261131, 2011.

[19] A. Lashkari, ” vol. 5, no. 1, pp. 17.

[20] A. Lashkari, $H$. Khalaf, $H$. Kazeminejad, "Effective delayed neutron fraction and prompt neutron lifetime of Tehran research reactor mixed-core", 2013, Annals of Nuclear Energy 55 (2013) 265-271 